\title{
See-saw nystagmus
}

\author{
J. M. FEIN AND R. D. B. WILLIAMS \\ From the Department of Psychiatry and Neurology, New York University Medical Center, New York, U.S.A
}

Nystagmus has been classically described as occurring in the horizontal, vertical, rotatory, or retractory planes in either a conjunctive or disjunctive fashion. There may be a fast and slow component or pendular oscillations.

In see-saw nystagmus a more complex series of movements are observable. The earliest description by Maddox in 1913 remains the classical reference. The patient was a 53-year-old carriage builder with failing sight and 'peculiar' eye movements. It appeared that the eyes when viewed from a distance exactly resembled a see-saw, one always rising as the other was falling - the rising of the right eye and the falling of the left eye was seen to be accompanied by a conjugate torsion to the left; the falling of the right and the rising of the left by conjugate torsion to the right. It is significant, as will be later evident, that this patient had bitemporal hemianopia.

The criteria thus established for see-saw nystagmus included a pendular dissociated nystagmus where the eyes rise and fall alternately, with an associated conjugate torsional nystagmus. These characteristically occur at a higher amplitude and lower frequency on downward gaze, and a lower amplitude and higher frequency on upward gaze.

Since its initial description, see-saw nystagmus has occupied a relatively obscure place in the literature because there are so few case reports illustrating this poorly understood phenomenon. To date, 15 cases have been described in the world literature, which provided speculation as to the pathophysiology involved. We have had the opportunity to study an interesting patient who illustrates features which, we believe, satisfy the criteria for see-saw nystagmus.

\section{CASE REPORT}

This 43-year-old Puerto Rican female was in her usual state of health until three years before admission when her family noticed that she abruptly and repeatedly veered to the left when walking. Several times a week she noted subjective dizziness without vertigo when standing or changing position. Two and a half years ago she noted a gradual loss of pain sensation in the left upper extremity. Shortly after this her family noted that her left shoulder 'went out of place'. This, however, caused hero little discomfort and, although all movements at the shoulder were limited, she was still able to perform gross and fine movements distally.

Her family had also noted that in the past two yearso her eyes oscillated in a peculiar fashion and that this wases becoming more prominent in the few weeks before heradmission. The patient denied headache, weight gain, polyuria, polydypsia, visual or auditory difficulty, as well $\vec{\omega}$ as motor complaints.

Her social history revealed that she was always introverted and 'slow'. She had attended the first grade for three years and thereafter did housework. She neveriw married and engaged in very little social activity other than with members of her immediate family. Her past medical history included diphtheria at the age of 5. Oree brother died of syphilis in adult life.

PHYSICAL EXAMINATION General physical examinatiann showed an obese, pleasant, middle-aged woman. Vitiliginous patches in the skin of the arms and back we present. There was a short systolic crescendo-des. crescendo grade II/VI ejection murmur at the pulmofico and aortic areas with no radiation. The liver edge was ${ }^{6}$ rounded but not tender and could be felt $2 \mathrm{~cm}$ below the right costal margin. The left deltoid muscle prominences was absent, with palpable dislocation of the left shoulder despite full passive range of motion. There were noo other bony abnormalities.

NEUROLOGICAL EXAMINATION On neurological examina- $\overrightarrow{\bar{\sigma}}$ tion, the patient showed normal affect with reduced3psychomotor activity. Calculation was done very poorly. Her judgement was poor and insight impaired but thereo was no evidence of bizarre ideation. Olfaction was intact bilaterally. Visual acuity was $20 / 30$ in each eye but corrected by pinhole vision to $20 / 20$. Visual fields were? normal by confrontation and tangent screen examination. The ocular fundi showed retinal hyperpigmentation but were otherwise benign. The external ocular movementso were intact and no ptosis was apparent. However, a 3 combined rotatory and vertical nystagmus was obvious.o On straight forward gaze there was intorsion and elevation of one eye associated with extorsion and depression $\frac{7}{0}$ of the other. At the completion of a half cycle, the previously extorting eye would intort and elevate and the N previously intorting eye would extort and depress (Fig. 1). On either lateral gaze, the nystagmus appeared 0 unchanged. On downward gaze the amplitude of vertical movements increased and its frequency decreased, while ${ }_{\sigma}$ 
- on upward gaze this relationship was reversed. There was never any head turning or tilting. The nystagmus persisted with either eye patched and was present on both near and distant gaze. Optokinetic nystagmus was normal in horizontal and vertical planes. Caloric responses were normal and temporarily interrupted the resting nystagmus.

The left corneal reflex was depressed, while the patient - reported absent corneal sensation. Pin sensation was depressed over the left face and forehead. Masseters were considered to be equal in volume and the jaw did not deviate on opening. Mild weakness of the left face and forehead was noted. Gross hearing, and Rinne and Weber tests were normal. There was distinct depression of the gag reflex on the left. The tongue was midline. Sternomastoid and trapezius function was intact.

- There was weakness of grasp and all fine movements in the left hand, as well as weakness of elbow flexion and extension. Limitation of all shoulder movements was marked. Analgesia and thermoanaesthesia of dermatomes C2-C8 on the left side was present, but touch, position sense, vibration, two-point discrimination, and stereognosis were intact. Aside from mild left-sided finger-to-nose dysmetria, probably related to weakness of the left - upper extremity, there were no other deficits in equilibratory and non-equilibratory co-ordination. The left pectoral, triceps, biceps, and finger flexion reflexes were absent. Other deep tendon reflexes were present and normal. Palmomental, snout, Hoffman, and pathological plantar reflexes were absent, and there were no abdominal reflexes.

, LABORATOKY DATA INVESTIGATIONS Complete blood count and urinalysis were normal. Fasting blood sugar,
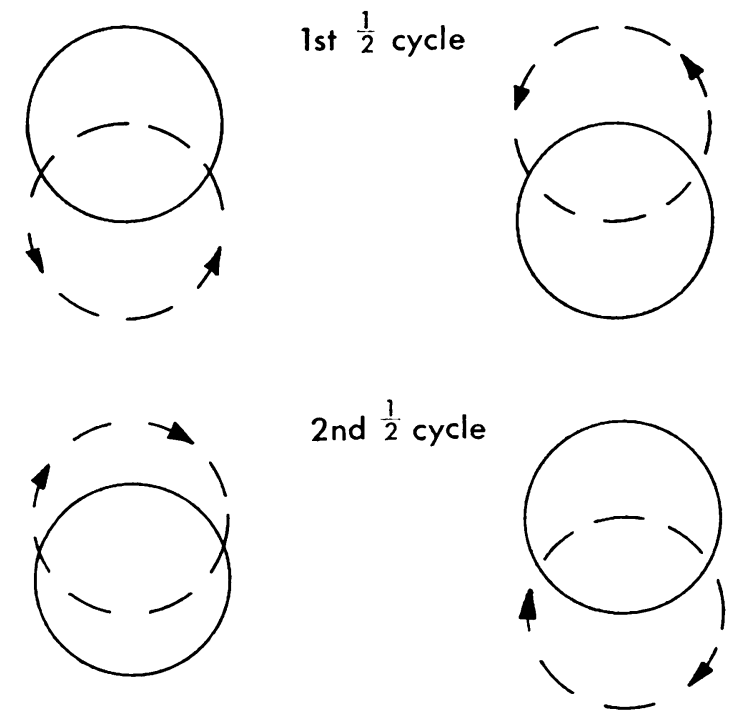

FIG. 1. Diagram of combined rotatory and vertical nystagmus. Closed circle = beginning of half cycle. Broken circle = end of half cycle.
BUN, creatinine, liver chemistries, uric acid, and PBI were normal. Serology and Tine test were negative. Chest radiograph was normal. Skull radiographs, echogram, and brain scan were normal.

Radiographs of the left shoulder showed destruction of the humoral head extending to the upper portion of the shaft. There was fragmentation and destruction of the glenoid fossa and sclerosis of the scapula and humerus. These were considered to reflect a neurogenic arthropathy.

Electroencephalography showed a normal basic frequency of $9 \mathrm{c} / \mathrm{s}$ with dominant alpha activity. There were very occasional symmetrical bursts of moderate voltage $5-7 \mathrm{c} / \mathrm{s}$ activity.

Nystagmography delineated the vertical components observed clinically (Fig. 2). On left lateral gaze there was vertical nystagmus slightly more prominent in the left eye and completely out of phase by $180^{\circ}$. On right lateral gaze there was also vertical nystagmus, left greater than right and out of phase. On upward gaze there was a more rapid, low amplitude nystagmus, the left eye minimally more prominent than the right. On downward gaze there was a slower, more prominent vertical nystagmus, left greater than right. A left brachial arteriogram showed $40 \%$ narrowing of the origin of the left vertebral artery. A left carotid arteriogram was normal. Pneumoencephalography demonstrated normal ventricles and cisterns. The parasellar region was well outlined and showed no abnormality.

\section{DISCUSSION}

Although pneumoencephalography did not show brain-stem enlargement, we feel that a clinical diagnosis of syringomyelia and syringobulbia is justified.

The symptomatology of syringomyelia is dependent on the location of the lesion. While usually interrupted at the ventral grey commissure, second order nociceptive fibres may be involved either at or near their origin in the dorsal horns, thus producing homolateral anaesthesia and thermoanaesthesia (Greenfield, 1963).

Syringobulbia is rarely limited to the brain-stem and more commonly involves also the upper cervical cord. It is typically a slit-like central cavity or transverse cavitation with midline dorsal and ventral extensions simulating the foetal cruciform central canal. Lying between the alar and basally arising nuclei, it is situated most commonly in a ventrolateral direction from the floor of the 4th ventricle toward the descending root of the trigeminal nerve. In this position it may give rise to facial anaesthesia and thermoanaesthesia. It less commonly occurs along the median raphe where it may involve the MLF, or, even more rarely, extends between the pyramid and inferior olive interrupting the emergent hypoglossal fibres.

Neuropathic arthropathies occur in approximately 
$25 \%$ of cases of syringomyelia, $80 \%$ of which occur in the upper extremities (Meyer, Stein, and Poppel, 1957). Eloesser (1917) demonstrated the role of trauma in neuropathic joint changes. Posterior root section followed by concomitant trauma produced changes typical of the arthropathy. Joint effusion is followed by relaxation of the ligaments with subsequent instability and deformity. There is thinning of articular cartilage, condensation of subchondral bone, marginal fractures, and formation of new bone outside of joint cavity.

Although rapid bony changes have been described, the usual interval between onset of detectable syringomyelia and osseous destruction is four to 12 months. The early stage, probably related to vascular $Z$ changes around the joint, is marked by soft-tissue swelling only. Calcification of the soft tissue ando active joint destruction then occur in the intermediate phase. Later, absorption of bone and progressive atrophy is marked.

The association of syringobulbia and see-saws nystagmus has not been previously reported.

The complexity of events and the inaccessibility. to direct monitoring of the structures involved have contributed to making see-saw nystagmus an inter- $\stackrel{?}{\rightarrow}$ esting but poorly understood phenomenon. Of the 15 cases previously noted in the world literature $\frac{\overline{\bar{O}}}{\bar{D}}$ (Table I), several theories have been put forward in $\frac{\bar{s}}{\overline{0}}$

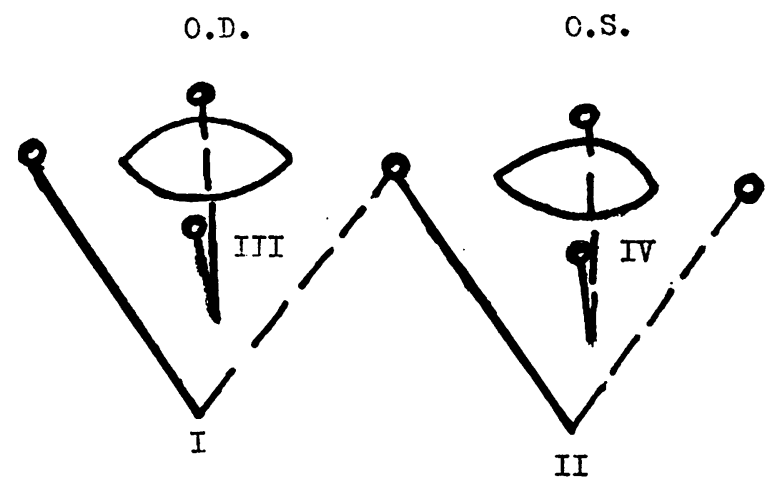

(a)

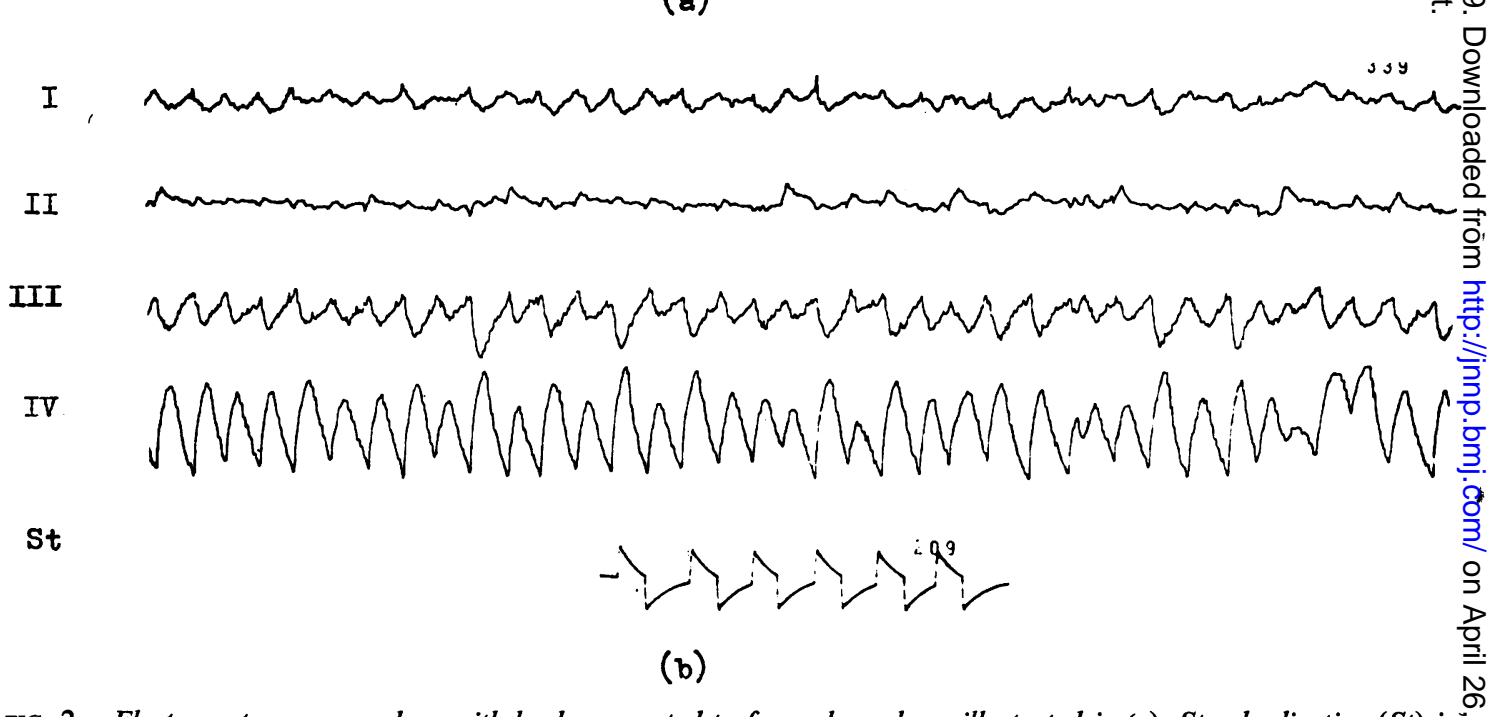

FIG. 2. Electronystagmogram done with leads connected to form channels as illustrated in (a). Standardization (St) is $50 \mathrm{uv}=4 \mathrm{~mm}$, time course $2.5 \mathrm{~cm}=1 \mathrm{sec}$. The excerpt (b) is during gaze to the left. The vertical component of the left eye is more prominent than the right, while horizontal component of the right is more prominent than the left. This $\mathrm{N}_{\mathrm{J}}$ relationship persisted, though less marked, in all directions of gaze as well as on straight forward gaze. 
an effort to explain the observed events. At least six patients were noted to have a bitemporal hemianopia related to chiasmal compression. Torsional nystagmus per se has not been produced by experimental stimulation of the optic pathways and visual system. It has been demonstrated in rabbits that horizontal nystagmus can be elicited with electrical stimulation anywhere along the optic nerve and tract (Gutman, Bergmann, Chaimovitz, and Costin, 1963). With optimal stimulation of the retina at $40 \mathrm{c} / \mathrm{s}$, an ipsilateral nystagmus is evident which is immediately abolished by chiasmal sectioning. The latter manoeuvre, however, greatly enhances the nystagmus response to tract stimulation, suggesting that retinal impulses somehow depress and moderate those arising in tract.

Lourie (1963) assumed an ocular disturbance involving the normal tonic influence of the macula, as the nystagmus first appeared in his patient after surgical removal of a chromophobe adenoma and surgery was followed by an improvement in visual acuity. The nystagmus was inhibited by visual fixation changes. Duke Elder (1949) has noted a rotatory component in some patients with miners nystagmus again supporting an ocular aetiology for this phenomenon. In other instances, however (Smith and Mark, 1959; Kinder and Howard, 1963; Schurr, 1963) nystagmus appeared unrelated to visual acuity and was not noted to diminish as acuity improved. Involvement of diencephalic and mesencephalic structure in patients with see-saw nystagmus (Table I) suggested that these regions are important in the production of such nystagmus. This was supported by experimental evidence that these areas control torsional and vertical extraocular movements. The zona incerta of the ventral thalamus and

TABLE I

KNOWN CASES OF SEE-SAW NYSTAGMUS

\begin{tabular}{|c|c|c|c|}
\hline Author & Vision & Aetiology & Comments \\
\hline Maddox (1913) & Bitemporal hemianopia & Unknown & \\
\hline Rucker (1946) & $\begin{array}{l}\text { Sparing of small central and inferior } \\
\text { temporal fields only }\end{array}$ & Diffuse choroiditis (?toxoplasma) & \\
\hline Larsen (1957) & & $\begin{array}{l}\text { Oligodendroglioma extending } \\
\text { frontal lobes to the anterior } \\
\text { margin of the pons }\end{array}$ & \\
\hline \multirow[t]{2}{*}{ Jensen (1959) } & $\begin{array}{l}\text { Case 1: 'Wallenberg syndrome'- } \\
\text { fields not plotted }\end{array}$ & Brain-stem vascular & $\begin{array}{l}\text { Case } 1: \text { nystagmus disappeared in } 2 \\
\text { days }\end{array}$ \\
\hline & $\begin{array}{l}\text { Case } 2 \text { : normal fields }(L) \text { medial } \\
\text { rectus palsy }(R) \text { extensor plantar } \\
\text { response }\end{array}$ & Brain-stem vascular & \\
\hline Smith and Mark (1959) & $\begin{array}{l}\text { Corrected v.a. } 20 / 2000 \text { O.D. } \\
\text { 20/300.S }\end{array}$ & $\begin{array}{l}\text { Suprasellar epidermoid cyst } \\
\text { compressing chiasm }\end{array}$ & $\begin{array}{l}\text { Acuity and fields improved post- } \\
\text { operatively }\end{array}$ \\
\hline Lourie (1963) & Bitemporal hemianopia & Chromophobe adenoma & $\begin{array}{l}\text { Nystagmus appeared post-operatively } \\
\text { with increasing acuity }\end{array}$ \\
\hline $\begin{array}{l}\text { Kinder and Howard } \\
\text { (1963) }\end{array}$ & $\begin{array}{l}\text { Diminished acuity (L) exotropia optic } \\
\text { atrophy, bitemporal hemianopia }\end{array}$ & Craniopharyngioma & $\begin{array}{l}\text { Nystagmus ceased as acuity improved } \\
\text { after surgery }\end{array}$ \\
\hline \multirow[t]{2}{*}{ Schurr (1963) } & $\begin{array}{l}\text { Case 1: Acuity normal, bitemporal } \\
\text { hemianopia }\end{array}$ & Craniopharyngioma & $\begin{array}{l}\text { Fields and nystagmus improved } \\
\text { post-operatively }\end{array}$ \\
\hline & $\begin{array}{l}\text { Case 2: Bilateral optic atrophy, } \\
\text { bitemporal hemianopia }\end{array}$ & Chromophobe adenoma & $\begin{array}{l}\text { Nystagmus disappeared } 3 \text { weeks } \\
\text { post-operatively and then returned }\end{array}$ \\
\hline Slatt and Nykiel (1964) & $\begin{array}{l}\text { Corr. acuity } 20 / 70 \text { O.D., } 20 / 200 \text { O.S. } \\
\text { normal fields }\end{array}$ & Congenital & $\begin{array}{l}\text { Amplitude reduced with contact } \\
\text { lenses and fixating an accommodative } \\
\text { target }\end{array}$ \\
\hline \multirow[t]{2}{*}{ Daroff (1967) } & $\begin{array}{l}\text { Case } 1: 20 / 200 \text { O.D. } 20 / 50 \text { O.S. mild } \\
\text { atrophy (bilateral) bitemporal hemia- } \\
\text { nopia }\end{array}$ & Chromophobe adenoma & $\begin{array}{l}\text { Nystagmus and medial rectus palsy } \\
\text { resolved incompletely }\end{array}$ \\
\hline & $\begin{array}{l}\text { Case } 2: 20 / 20 \text { O.U. normal fields, } \\
\text { (L) medial rectus palsy }\end{array}$ & Brain-stem vascular & \\
\hline Walsh (unpublished) & $\begin{array}{l}\text { Case 1: } 20 / 30 \text { O.V. fields and fundi } \\
\text { normal } \\
\text { Case 2: bitemporal hemianopia }\end{array}$ & Congenital & $\begin{array}{l}\text { Dissociated vertical nystagmus, } \\
\text { torsional movements not pronounced }\end{array}$ \\
\hline
\end{tabular}


the interstitial nucleus of Cajal in the rostral midbrain, in particular, are implicated. A combination of vertical and rotary nystagmus has been produced by introducing chemicals into the third ventricle, which stimulates the structures mentioned above (Szekely and Spiegel, 1963), and there is other evidence that the final co-ordination of rotary and vertical eye movements is in the rostral midbrain nuclei (Szentágothai, 1943). Hyde and Eliasson(1957), Hyde and Eason (1959), and Hyde and Toczek (1962) stimulated the zona incerta and interstitial nucleus electrically and reported an admixture of torsional and vertical movements and in later experiments noted that stimulation of the zona incerta resulted in activation of efferents which descend to the interstitial nucleus.

Torsional movements, unlike vertical and horizontal movements have not been produced by cortical stimulation and are probably unrelated to frontal lobe activity or volition (Cogan, 1956). That they may be elicited by rotating a visual field presumes that there is representation in the occipital lobes. At this point, more detailed localization seems unsubstantiated.

Two-thirds of the patients previously reported with see-saw nystagmus have had demonstrated parasellar lesions. Indeed the phenomenon has been considered a strong clue in localizing pathology to this region. The role of the brain-stem vestibular system has, however, not been considered in this torsional nystagmus, although torsional movements are produced by appropriate vestibular stimuli. Ocular torsion accompanying head tilt is reflexly mediated through the labyrinth and vestibular nuclei. Torsion is elicited (Tschermak, 1931) by head tilt (maximal at $60^{\circ}$ ) and head rotation and abolished by labyrinthectomy (Kompanejetz, 1928). It occurs to one side most effectively with stimulation of the contralateral labyrinth. Experimental (Leidler, 1916) and clinical evidence (Marburg, 1912) indicate that of the antero-medial vestibular nuclei concerned in eye movements, the most anterior mediates vertical eye movements and the most posterior torsional movements.

Stimulation experiments in rabbits (Montandon and Monnier, 1964) demonstrate that the superior and to a lesser extent the medial vestibular nuclei produce a slow horizontal contraversive deviation of eyes and head with a rotatory component about the longitudinal axis and elevation of the contralateral eye. This central vestibular nystagmus differs from that produced by diencephalic stimulation in the superimposition of a vertical upon a horizontal component giving an appearance of rotation.

Of interest is the abrupt onset of a gait ataxia preceding the symptoms of a syrinx in this patient.
Brachial arteriography demonstrated $40 \%$ narrowing of the origin of the left vertebral artery. Cavitation of the cervical cord incident to vascular occlusion has been demonstrated both clinically and experiment $\frac{5}{0}$ ally. Netsky (1953) postulated congenital intramedullary vascular anomalies as the substrate for eight cases of syringomyelia. Arachnoiditis and? resulting vascular disruption gave rise to cavitation according to Nielsen (1957). By ligating the anterior. spinal artery, Tauber and Langworthy $(1935)$ produced cavitations resembling those of true? syringomyelia.

Jensen (1959) reported the case of a 55-year-old음 man with an apoplectic onset of diplopia, a partia Wallenberg syndrome, and see-saw nystagmus. Localization of the infarction to the lower lefte brain-stem is strikingly similar to our own case.

Finally, Merritt (1963) notes that a cervical syrinx may interrupt the medial longitudinal fasiculus and $\vec{\omega}$ produce a horizontal nystagmus, while a medullarye syrinx may give rise to a rotary nystagmus. The latter is presumably related to disconnection of vestibular circuits, although the character of the observed nystagmus was not detailed.

\section{SUMMARY}

See-saw nystagmus has been regarded as heralding the presence of a parasellar mass lesion. We hå e $\mathrm{C}_{\text {. }}$ offered an illustration of how pontine and medullaty $\overrightarrow{0}$ dysfunction can give rise to the same phenomenof. A review of the experimental and clinical literature illustrates that the mechanisms responsible areo probably represented on multiple levels. The entity should, therefore, not be equated in specificityo with other signs traditionally associated withő parasellar disease.

We would like to express our thanks to Dr. Clark T Randt for his helpful criticism and to Miss Doneva Russell for the preparation of the manuscript.

\section{REFERENCES}

Cogan, D. G. (1956). Neurology of the Ocular Muscles, 2nd ed.? p. 127. Thomas: Springfield, Illinois.

Daroff, R. B. (1967). See-saw nystagmus. Neurology, 15, 874-877.

Duke Elder, W. S. (1949). See-saw nystagmus, p. 4232 in Textbook of Ophthalmology, vol. 4. C. V. Mosby: St. Louis, Missouri.

Eloesser, L. (1917). On the nature of neuropathic affections of the joints. Ann. Surg., 66, 201-207.

Greenfield, J. G. (1963). Neuropathology, 2nd ed., compiled by을 W. Blackwood, W. H. McMenemy, A. Meyer, R. M. Norman, and D. S. Russell, p. 334. Williams and Wilkins: Baltimore, N Maryland.

Gutman, J., Bergmann, F., Chaimovitz, M., and Costin, A. (1963). N Nystagmus evoked by stimulation of the optic pathways in the rabbit. Exp. Neurol., 8, 132-142.

Hyde, J. E., and Eliasson, S. G. (1957). Brainstem induced eye move- $\sigma$ ments in cats. J. comp. Neurol., 108, 139-172. 
- , and Eason, R. G. (1959). Characteristics of ocular movements evoked by stimulation of brainstem of cat. J. Neurophysiol. 22, 666-678.

- - , and Toczek, S. (1962). Functional relation of interstitial nucleus to rotary movements evoked from zona incerta stimulation. Ibid., 25, 455-466.

Jensen, O. A. (1959). Seesaw nystagmus. Brit. J. Ophthal., 43, 225-229.

Kompanejetz, S. (1928). Investigation on the counterrolling of the eyes in optimum head positions. Acta oto-laryng. (Stockh.), 12, 332-350.

Kinder, R. S. L., and Howard, G. M. (1963). See-saw nystagmus. An unusual sign of lesions near the third ventricle. Amer. $J$. Dis. Child., 106, 331-332.

Larsen, V. (1957). Et tilfaelde of vippenystagmus. Ugeskr. Laeg., $119,947-950$.

Leidler, R. (1916). Experimentelle Untersuchungen uber das Endigungsgebiet des Nervus vestibularis. 2. Mitteilung. Arb. neurol. Inst. Univ. Wien., 21, 151.

Lourie, H. (1963). See-saw nystagmus. Case report elucidating the mechanism. Arch. Neurol. (Chic.), 9, 531-533.

Maddox, E. E. (1913). See-saw nystagmus with bitemporal hemiaropia. Proc. roy. Soc. Med., Sect. Neurol., Ophthal., 7, xii-xiii.

Marburg, O. (1912). Zur Lokalisation des Nystagmus. Neurol. Centralbl., 31, 1366-1371.

Merritt, H. H. (1963). A Textbook of Neurology, 3rd ed., p. 517. Lea and Febiger: New York.

Meyer, G. A., Stein, J., and Poppel, M. H. (1957). Rapid osseous changes in syringomyelia. Radiology, 69, 415-418.
Montandon, P., and Monnier, M. (1964). Correlations of the diencephalic nystagmogenic area with the bulbo-vestibular nystagmogenic area. Brain, 87, 673-690.

Netsky, M. G. (1953). Syringomyelia: a clinicopathologic study. Arch. Neurol. Psychiat. (Chic.), 30, 741-777.

Nielsen, J. M. (1957). The syringomyelic syndrome. Bull. Los Angeles neurol. Soc., 22, 151-158.

Rucker, C. W. (1946). Seesaw nystagmus associated with choroiditis and positive neutralization test for toxoplasma. Arch. Ophthal., 35, 301-302.

Schurr, P. H. (1963). See-saw nystagmus. Proc. rsy. Soc. Med., 56, 808-810.

Slatt, B., and Nykiel, F. (1964). See-saw nystagmus. Amer. J. Opthal., 58, 1016-1021.

Smith, J. L., and Mark, V. H. (1959). See-saw nystagmus with suprasellar epidermoid tumor. Arch. Ophthal., 62, 280-283.

Szekeley, E. G., and Spiegel, E. A. (1963). Vertical nystagmus induced by injection of stimulating substances into the striatum, third or lateral ventricle. Neurology (Minneap.), 13, 306-314.

- (1943). Die zentrale Innervation der Augenbewegungen. Arch. Psychiat. Nervenkr., 116, 721-760.

Tauber, E. S., and Langworthy, O. R. (1935). A study of syringomyelia and the formation of cavities in the spinal cord. $J$. nerv. ment. Dis., 81, 245-264.

Tschermak, A. (1931). Augenbewegungen, pp. 1001-1094 in Handbuch der Normalen und Pathologischen Physiologie, Vol. 12, edited by A. Bethe, G. von Bergmann, E. Embden, and A. Ellinger. Springer: Berlin. 